\title{
New Data Reveal More Americans Than Ever Have Epilepsy
}

\author{
An Expert Interview with Michael Privitera \\ University of Cincinnati College of Medicine and Epilepsy Center at UC Gardner Neuroscience Institute, Cincinnati, $\mathrm{OH}, \mathrm{US}$
}

DOl: https://doi.org/10.17925/USN.2018.14.1.23

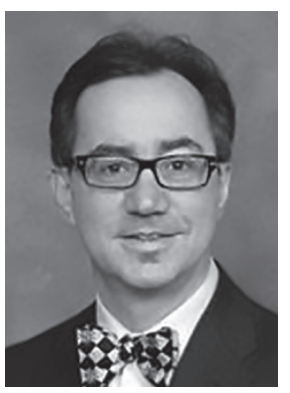

Michael Privitera MD

Michael Privitera MD is the Director of the Epilepsy Center at the University of Cincinnati Gardner Neuroscience Institute. He has been a neurologist at the University of Cincinnati Medical Center for more than 25 years and a Professor of Neurology at the University of Cincinnati College of Medicine for 14 of those years. Dr. Privitera is an internationally recognized expert on advanced treatments for epilepsy and has dedicated his career to discovering new treatments and caring for people with epilepsy. In addition to his extensive medical experience, Dr. Privitera served as the 2016 president of the American Epilepsy Society.

\section{Keywords}

Epilepsy, prevalence, diagnosis, management

Disclosure: Michael Privitera has nothing to disclose in relation to this article.

Review Process: This is an expert interview and as such, has not undergone the journal's standard peer review process.

Authorship: The named author meets the International Committee of Medical Journal Editors (ICMJE) criteria for authorship of this manuscript, takes responsibility for the integrity of the work as a whole, and has given final approval for the version to be published.

Open Access: This article is published under the Creative commons Attribution Noncommercial License, which permits any noncommercial use, distribution, adaptation, and reproduction provided the original author and source are given appropriate credit. (๑) The Author 2018.

Received: August 31, 2017

Published Online: January 22, 2018

Citation: US Neurology. 2018;14(1):23-24

Corresponding Author: Michael Privitera, University of Cincinnati College of Medicine and Epilepsy Center at UC Gardner Neuroscience Institute, Cincinnati, OH 45267, US. E: michael.privitera@uc.edu

Support: No funding was received in the publication of this article.
A new Centers for Disease Control and Prevention (CDC) study published in August 2017 reported national and state estimates of the numbers of adults and children with active epilepsy in the US in 2015. ' In an expert interview, Dr. Privitera, past president of the American Epilepsy Society (AES, 2016), discusses the implications of the latest data including the public health impact, how to recognize the signs and symptoms of epilepsy, and how AES is partnering with CDC to provide educational resources about epilepsy and keep children and adults with epilepsy safe in their communities.

\section{Q. What does the CDC report tell us about the prevalence of epilepsy?}

Most people are surprised to find that the prevalence of epilepsy is this high. Remarkably, this new report shows that current estimates of epilepsy prevalence are even higher than the estimates based on research summarized in 2010. Affecting 3.4 million US residents, epilepsy is not a rare condition. The CDC data was quite accurate and based on direct questions in household surveys of general health. People were asked about doctor-diagnosed epilepsy, seizure medications, and seizures in the past year.

\section{Q. Why is the prevalence of epilepsy increasing?}

The CDC believes the increases are mostly based on population growth, but other factors, like increased willingness to disclose that one has epilepsy could play a part. It is possible that improvements in our ability to diagnose epilepsy may have also led to the reported increased prevalence.

\section{Q. What are the major challenges to the diagnosis of epilepsy?}

The major challenge to making a diagnosis of epilepsy is that seizures can have a wide variety of manifestations. Most people are familiar with generalized tonic-clonic seizures (convulsions), but are less familiar with seizures that simply impair awareness (staring spells) without motor movements. Many patients who are diagnosed with epilepsy go months or years without a correct diagnosis. In some cases, the first tonic-clonic seizure is what brings the patient to the doctor, but seizures with impaired awareness or other subtle symptoms may have gone undiagnosed for years. The principal manifestation of a seizure usually relates to the part of the brain where the seizure originates, adding more complexity to the clinical signs. In some syndromes, for example myoclonic epilepsy, the seizure may be a jerk of the body or extremities that only lasts a second. In infantile spasms, a severe epilepsy syndrome of children, the seizures are short, but may occur hundreds of times per day. 
Another challenge to making the seizure diagnosis is that when a patient sees the doctor for evaluation, the details of the seizure are often provided by an observer. In a substantial number of cases, diagnostic studies performed between seizures may be negative. In these cases, the diagnosis depends on an accurate history, but the patient may have no memory for the events of the seizure itself, and an observer may not have been present at the start of the seizure.

\section{Q. How can families and caregivers improve their recognition of seizures?}

Seizures in one particular patient are usually stereotyped, so knowing the typical manifestations of the seizures in that specific patient is important. Improved seizure alert devices that rely on detection of movement, or other detectable biological changes, have improved seizure detection. Families and caregivers can also go to resources like the CDC website (www.cdc.gov/epilepsy/index.html) which includes extensive information written for the lay public about epilepsy and how to recognize it.

\section{Q. What initiatives are the CDC undertaking to improve the management of epilepsy?}

The CDC has funded a wide variety of initiatives to improve the management of epilepsy. First, through rigorous epidemiology studies the prevalence

of epilepsy can be determined more accurately so that resources can be provided for care and research. Second, CDC has funded the Managing Epilepsy Well network that has tested and published evidence based, nonpharmacologic methods that can be adjuncts for seizure control, memory problems often faced by people with epilepsy, and depression, which is more common in epilepsy than in the general population or even most comparable chronic diseases. Some of these programs also include stress reduction methods because stress is the most commonly patient-reported seizure precipitant. Third, the CDC has funded a nationwide epilepsy education and awareness program through the Epilepsy Foundation aimed at the general public, patients themselves, and healthcare providers. The American Epilepsy Society, along with a number of other professional societies and patient advocacy organizations, are partners in this collaborative effort. This program aims to educate the public, but also to make people with epilepsy and healthcare providers more aware of standard and advanced treatments available. For example, many epilepsy specialists believe that epilepsy surgery for people with medicationresistant epilepsy is safer and more effective than it has ever been, yet is woefully underutilized. Also, newer antiepileptic drugs are usually better tolerated with fewer drug-drug interactions than older drugs. The goal of epilepsy treatment should be no seizures, no side effects. Although this goal is not always attainable, everyone should be aware of new advances in treatment that make it achievable by many more of the 3.4 million Americans with epilepsy than ever before. $\square$

1. Zack MM, Kobau R. National and state estimates of the numbers of adults and children with active epilepsy — United States, 2015. MMWR Morb Mortal Wkly Rep. 2017;66:821-5. DOI. Available at: http://dx.doi.org/10.15585/mmwr.mm6631a1 (accessed September 21, 2017) 